\title{
A Prospective Comparison of Wavefront-Guided LASIK versus Wavefront-Guided PRK After Previous Keratorefractive Surgery
}

This article was published in the following Dove Press journal: Clinical Ophthalmology

\author{
Michele D Lee $\mathbb{D}^{\prime}$ \\ Lisa $Y$ Chen $^{2}$ \\ Elaine $M \operatorname{Tran}^{2}$ \\ Edward E Manche ${ }^{2}$ \\ 'Department of Ophthalmology, \\ University of Washington, Seattle, WA, \\ USA; ${ }^{2}$ Byers Eye Institute, Stanford \\ University School of Medicine, Palo Alto, \\ CA, USA
}

Purpose: To compare the results of retreatment with wavefront-guided LASIK versus wavefront-guided PRK for residual refractive error following previous myopic keratorefractive surgery.

Methods: In this prospective study, 32 eyes of 28 patients after prior myopic keratorefractive surgery underwent retreatment with flap-lift wavefront-guided LASIK $(n=12)$ or wavefront-guided PRK $(n=20)$ for residual refractive error. Safety, efficacy, predictability, and wavefront outcomes were evaluated.

Results: At last follow-up, both LASIK and PRK retreatment resulted in similar improvement in visual acuity with respective mean \pm standard deviation (SD) uncorrected distance visual acuity of $-0.07 \pm 0.11 \operatorname{logMAR}$ and $-0.06 \pm 0.13 \operatorname{logMAR}(\mathrm{p}=0.87)$. In the study, $16.7 \%$ of LASIK and $33.3 \%$ of PRK eyes gained one or more lines of best-corrected distance visual acuity (CDVA), while $16.7 \%$ and $9.5 \%$ of eyes lost one or more lines of CDVA with LASIK and PRK, respectively. One hundred \% of LASIK eyes and $89.5 \%$ of PRK eyes were within \pm 0.50 diopters of emmetropia. Wavefront analysis demonstrated similar reductions in total RMS error higher-order aberrations $(\mathrm{p}=0.84)$ with no difference in coma, trefoil, or spherical aberration between eyes undergoing LASIK or PRK retreatment.

Conclusion: Wavefront-guided LASIK and wavefront-guided PRK following previous keratorefractive surgery demonstrate similar safety, efficacy, and predictability with comparable wavefront outcomes.

Keywords: LASIK, PRK, refractive surgery, retreatment

\section{Introduction}

Refractive surgery, such as laser-in-situ keratomileusis (LASIK) and photorefractive keratectomy (PRK), is frequently performed for the treatment of myopia. ${ }^{1,2}$ Due to the quick and nearly painless recovery it offers, LASIK is the most commonly performed refractive procedure in the US. However, there are additional risks with LASIK compared to PRK, including corneal ectasia and flap complications. $^{3-6}$ To date, studies comparing the two procedures have focused on clinical outcomes after primary surgery, such as visual outcomes, induction of higher order aberrations (HOAs), post-operative complications, and quality of vision. $^{7-12}$

Even with overall excellent results, refractive surgery may induce residual or postoperative refractive error that may require an additional retreatment procedure, with a reported rate of $2.30-6.3 \%$ of eyes requiring retreatment. ${ }^{13-15}$ In addition to
Correspondence: Edward E Manche Byers Eye Institute, Stanford University School of Medicine, 2452 Watson Court, Palo Alto, CA 94303, USA

Tel + I 650-723-6995

$\mathrm{Fax}+1$ 650-498-6488

Email Edward.Manche@stanford.edu 
the attendant risks that accompany refractive procedures, LASIK retreatment carries additional flap-related complications, particularly epithelial ingrowth which has a reported incidence rate of $2.3-20 \% .{ }^{16-22}$ The largest retrospective study by Caster et al reported the results of 3866 primary and 646 retreatment LASIK cases, demonstrating that the incidence of clinically significant epithelial downgrowth was higher in flap-lift retreatment LASIK (2.3\%) compared to primary LASIK $(0 \%){ }^{23}$ In the same study, when flap-lift LASIK retreatment was performed three or more years after primary LASIK, the risk of epithelial downgrowth was significantly increased to $7.7 \%$. Most recently, a retrospective study by Chan et al suggested that factors such as the use of a bandage contact lens and various flap-lift techniques, as well as increasing patient age, may be associated with an increased rate of epithelial ingrowth. $^{22}$

Various modalities have been deemed predictable, effective, and safe to use for enhancement after prior keratorefractive surgery. Jin et al evaluated outcomes of LASIK retreatment after wavefront-guided and standard LASIK treatments, Montague et al reported enhancement results using CustomVue wavefront-guided LASIK in 120 eyes of 102 patients, Kashani et al assessed wavefrontguided LASIK retreatment after initial wavefront-guided LASIK, and Broderick et al looked at wavefront-optimized PRK after prior PRK, LASIK, and LASEK; the outcomes from these studies were comparable. ${ }^{24-28}$

There are a limited number of studies comparing PRK versus LASIK as retreatment modalities. Schallhorn et al performed a comparative study to evaluate the efficacy of wavefront-guided PRK versus a LASIK flap lift on patients who have had prior LASIK. ${ }^{29}$ In this retrospective study, 119 eyes had flap-lift enhancement, while 171 eyes underwent PRK, which was performed over the LASIK flap. There was no significant difference in postoperative efficacy, safety, and predictably; however, $22(18.5 \%)$ of LASIK retreated eyes had epithelial ingrowth and $5.3 \%$ of PRK retreated eyes had grade I haze, which resolved within 6 months. While there was a trend for better outcomes in flap-lift enhancements, there was no statistical significance. Furthermore, it was difficult to directly compare the two enhancement techniques as this was a retrospective study; there were a variety of factors that may have influenced the choice of treatment and outcomes.

To our knowledge, there has not been a study that prospectively compares the results of retreatment with LASIK versus PRK. In our study, we prospectively evaluate the results of retreatment with flap-lift wavefront-guided LASIK versus wavefront-guided PRK for residual refractive error following previous keratorefractive surgery.

\section{Materials and Methods}

Thirty-two eyes of 28 patients' status post prior refractive surgery for myopia with residual refractive error were recruited and enrolled from the refractive surgery service at Byers Eye Institute at Stanford Hospital and Clinics. In order to be included in the study, patients were required to be older than 21 years of age, have a history of stable refractions $(<0.5$ diopters of sphere or cylinder in 1 year prior to surgery), correct to $20 / 20$ or better in both eyes at the preoperative visit, and participate in scheduled followup visits.

We have previously described our exclusion criteria for primary refractive surgery. ${ }^{2,12}$ In brief, subjects were excluded from primary refractive surgery due to cornea pathology, including severe dry eye, infection, or warpage, rigid gas-permeable lens use, a diagnosis of a systemic disease that may potentially involve the cornea, a residual stromal bed of $250 \mu \mathrm{m}$ or less, a large difference between manifest and cycloplegic refractions $(>0.75$ diopters of sphere or $>0.50$ diopters of cylinder), known allergy to study drugs, and/or involvement in another ophthalmic device or drug trial.

This study was approved by the Stanford University Institutional Review Board and this study was conducted in accordance with the Declaration of Helsinki, and each patient underwent an informed consent prior to enrollment in the study. A thorough examination was performed, including a slit-lamp examination, intraocular pressure measurements, infrared pupillometry (photopic and scotopic), best-corrected visual acuity (BCVA) under 5\% and $25 \%$ contrast sensitivity conditions, manifest and cycloplegic refraction, and a dilated fundus exam.

Each study eye underwent corneal topography. Wavefront aberrometry was performed using the Visx CustomVue WaveScan Aberrometer and measured with an undilated pupil. The acquisition with the clearest centroid image out of six wavefront aberrations performed per study eye was used for analysis. To account for the potential variability caused by different pupil diameters, aberrometry images within $\pm 0.25 \mathrm{~mm}$ of the preoperative measurement were used for data analysis, and all data were normalized to a $5.0 \mathrm{~mm}$ pupil using the Wavescan aberrometer Zernike tool. 
Surgeries were performed by a single surgeon (E.E.M) at a single facility (Byers Eye Institute, Eye Laser Center) using the AMO VISX S4 CustomVue IR excimer laser. Each eye was pre-treated with proparacaine hydrochloride 0.5\% (Ophthetic; Allergan, Irvine, $\mathrm{CA}$ ), ketorolac tromethamine ophthalmic solution $0.4 \%$ (Acular LS; Allergan, Irvine, CA), and moxifloxacin hydrochloride ophthalmic solution $0.5 \%$ (Vigamox; Alcon, Fort Worth, TX). LASIK enhancement surgery was performed in eyes that had undergone previous femtosecond-LASIK surgery less than two years prior and PRK surgery was performed for prior LASIK-treated eyes more than two years out. All patients who had previous PRK underwent repeat PRK surgery.

LASIK flaps were re-lifted for LASIK enhancement surgery. The edge of the original femtosecond LASIK flap was identified and a LASIK flap lifter was used to break into the edge of the flap. The flap edge was scored all around the LASIK flap and was lifted with the lifter. The ablation was performed and the flap repositioned. A bandage contact lens was placed at the conclusion of the case and removed on postoperative day one in all cases. Post-operative care
Table I Pretreatment Uncorrected Visual Acuity, Manifest Refraction, and Aberrations Prior to LASIK or PRK Retreatment

\begin{tabular}{|l|l|l|l|}
\hline & $\begin{array}{l}\text { LASIK } \\
\text { Retreatment }\end{array}$ & $\begin{array}{l}\text { PRK } \\
\text { Retreatment }\end{array}$ & P-value \\
\hline $\begin{array}{l}\text { Uncorrected Visual Acuity } \\
\text { (logMAR) }\end{array}$ & $0.20 \pm 0.11$ & $0.23 \pm 0.16$ & 0.48 \\
Spherical Equivalent (D) & $-0.54 \pm 0.80$ & $-0.63 \pm 0.91$ & 0.79 \\
Cylinder (D) & $0.48 \pm 0.38$ & $0.58 \pm 0.23$ & 0.38 \\
Coma & $0.23 \pm 0.15$ & $0.26 \pm 0.14$ & 0.52 \\
Trefoil & $0.20 \pm 0.09$ & $0.17 \pm 0.11$ & 0.15 \\
Spherical Aberrations & $0.26 \pm 0.19$ & $0.32 \pm 0.20$ & 0.44 \\
Root-Mean-Square (RMS) & $0.48 \pm 0.18$ & $0.53 \pm 0.18$ & 0.55 \\
Error $(\mu)$ & & & \\
\hline
\end{tabular}

included topical fluoroquinolone (moxifloxacin) four times a day and a topical steroid four times a day for 1 week. In eyes undergoing PRK after previous PRK, the epithelium was removed using an Amoils epithelial scrubber over an $8.0 \mathrm{~mm}$ zone centered over the pupil. In eyes undergoing PRK after the previous LASIK, the epithelium was removed by applying $20 \%$ alcohol to the center of the cornea for 45 seconds using a corneal well.

\section{Uncorrected Distance Visual Acuity}

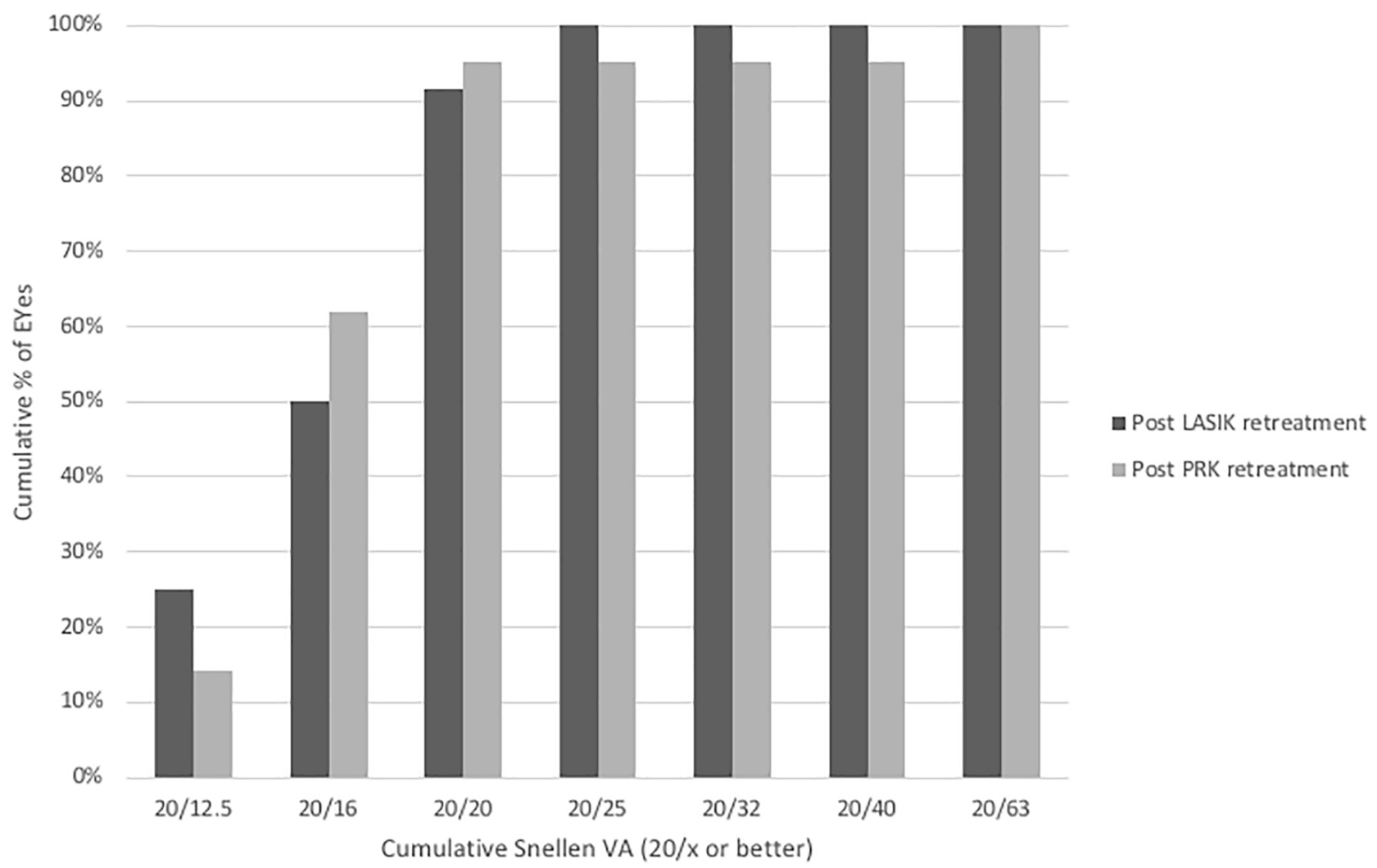

Figure I Percentage of eyes achieving uncorrected Snellen distance visual acuity at the last postoperative visit. 
Table 2 Uncorrected Visual Acuity, Manifest Refraction, and Aberrations After LASIK or PRK Retreatment

\begin{tabular}{|l|l|l|l|}
\hline & $\begin{array}{l}\text { LASIK } \\
\text { Retreatment }\end{array}$ & $\begin{array}{l}\text { PRK } \\
\text { Retreatment }\end{array}$ & P-value \\
\hline $\begin{array}{l}\text { Uncorrected Visual Acuity } \\
\text { (logMAR) }\end{array}$ & $-0.07 \pm 0.10$ & $-0.06 \pm 0.13$ & 0.87 \\
Spherical Equivalent (D) & $-0.09 \pm 0.24$ & $-0.05 \pm 0.43$ & 0.77 \\
Cylinder (D) & $0.13 \pm 0.20$ & $0.28 \pm 0.25$ & 0.07 \\
Coma & $0.28 \pm 0.14$ & $0.22 \pm 0.14$ & 0.24 \\
Trefoil & $0.13 \pm 0.07$ & $0.13 \pm 0.08$ & 0.94 \\
Spherical Aberrations & $0.26 \pm 0.19$ & $0.29 \pm 0.22$ & 0.76 \\
Root-Mean-Square (RMS) & $0.47 \pm 0.15$ & $0.45 \pm 0.20$ & 0.72 \\
Error $(\mu)$ & & & \\
\hline
\end{tabular}

Photoablation was performed using the VISX Star CustomVue S4 IR excimer laser system with autocentration and iris recognition. Mitomycin C $0.02 \%$ was applied for 12 seconds in all cases. A bandage contact lens was placed for healing and patients were instructed to use topical fluoroquinolone such as moxifloxacin or ciprofloxacin four times a day until the epithelium was healed and a topical steroid drop four times a day for 2 weeks, then two times a day for 2 weeks.

Patients were seen at prescribed intervals of 1 day, 1 week, 1 month, 3 months, 6 months, and 12 months after the procedure. Microsoft Excel Software (Microsoft Corporation, Redmond, WA) was used for analysis and a paired students $t$-test was used to perform all comparisons of the means. P-values were 2-sided and significant when $\mathrm{p}<0.05$.

\section{Results}

All eyes enrolled in the study underwent successful retreatment with LASIK or PRK. There were 24 females (75.0\%) and 8 males $(25.0 \%)$ with an average age of $40.2 \pm 11.0$ years (range 24-57 years). Twelve eyes of 12 patients with previous femtosecond LASIK received flap-lift LASIK retreatment. Twenty eyes of 17 patients with previous LASIK or PRK received PRK retreatment; of these, 8 eyes of 8 patients had previous LASIK and 12 eyes of 9 patients had previous PRK. The average time between the primary surgery and the retreatment was $716.3 \pm 729.6$ days. Eyes that underwent LASIK had retreatment surgery within 24 months ( $434.6 \pm 92.7$ days, range 322 to 653 days $)$ and eyes that underwent PRK had retreatment surgery between 322 and 4012 days ( $885.3 \pm 885.1$ days, range 322 to 4012 days). All eyes were retreated due to residual refractive error. No eyes were treated for any other reason (ie small optical zones, decentration), and all eyes were primary undercorrections.

Preoperatively, LASIK retreatment eyes had an average spherical equivalent of $-0.30 \pm 0.77$ diopters while PRK retreatment eyes had an average spherical equivalent of $-0.34 \pm 0.90$ diopters $(\mathrm{p}=0.93$, Table 1$)$. LASIK retreatment eyes had an average cylinder of $0.48 \pm 0.38$ diopters compared to $0.58 \pm 0.23$ diopters in PRK retreatment eyes ( $\mathrm{p}$ $=0.38$ ). Average spherical aberration in LASIK retreatment eyes was $0.26 \pm 0.19$; PRK retreatment eyes had an average spherical aberration of $0.32 \pm 0.20(\mathrm{p}=0.44)$.

Measurements taken at the last follow-up date were used for post-treatment analysis; the mean time in months for the last follow-up was $6.3 \pm 4.4$ months in the LASIK retreatment group and $8.9 \pm 3.8$ months in the PRK retreatment group $(\mathrm{p}=0.12)$. After retreatment, $92 \%$ and $95 \%$ of postLASIK and post-PRK-treated eyes had an uncorrected Snellen visual acuity of 20/20 or better (Figure 1). Posttreatment spherical equivalent of the LASIK retreatment and PRK retreatment groups were $-0.09 \pm 0.24$ diopters and $-0.07 \pm 0.43$ diopters $(\mathrm{p}=0.89$, Table 2). One

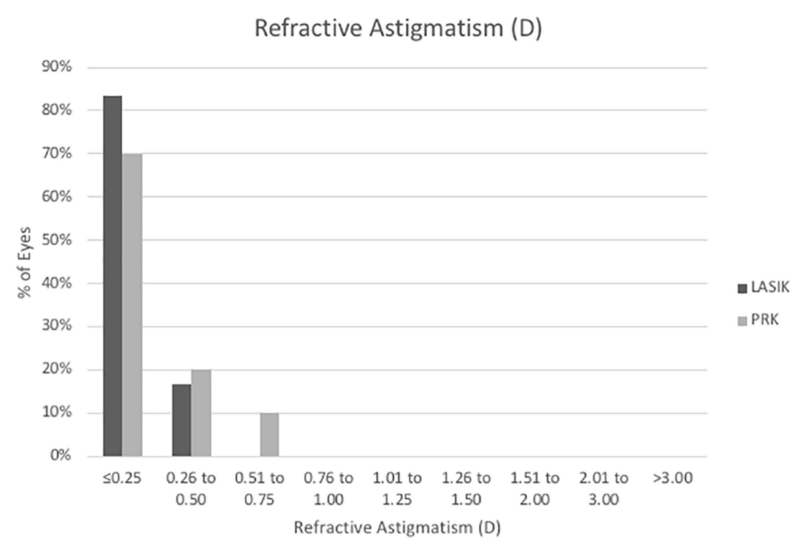

Figure 2 Comparing predictability between LASIK and PRK retreatment. Histogram of spherical equivalent refraction after enhancement (left). Histogram of refractive astigmatism after enhancement (right). 


\section{Spherical Equivalent Refraction Attempted vs. Achieved}

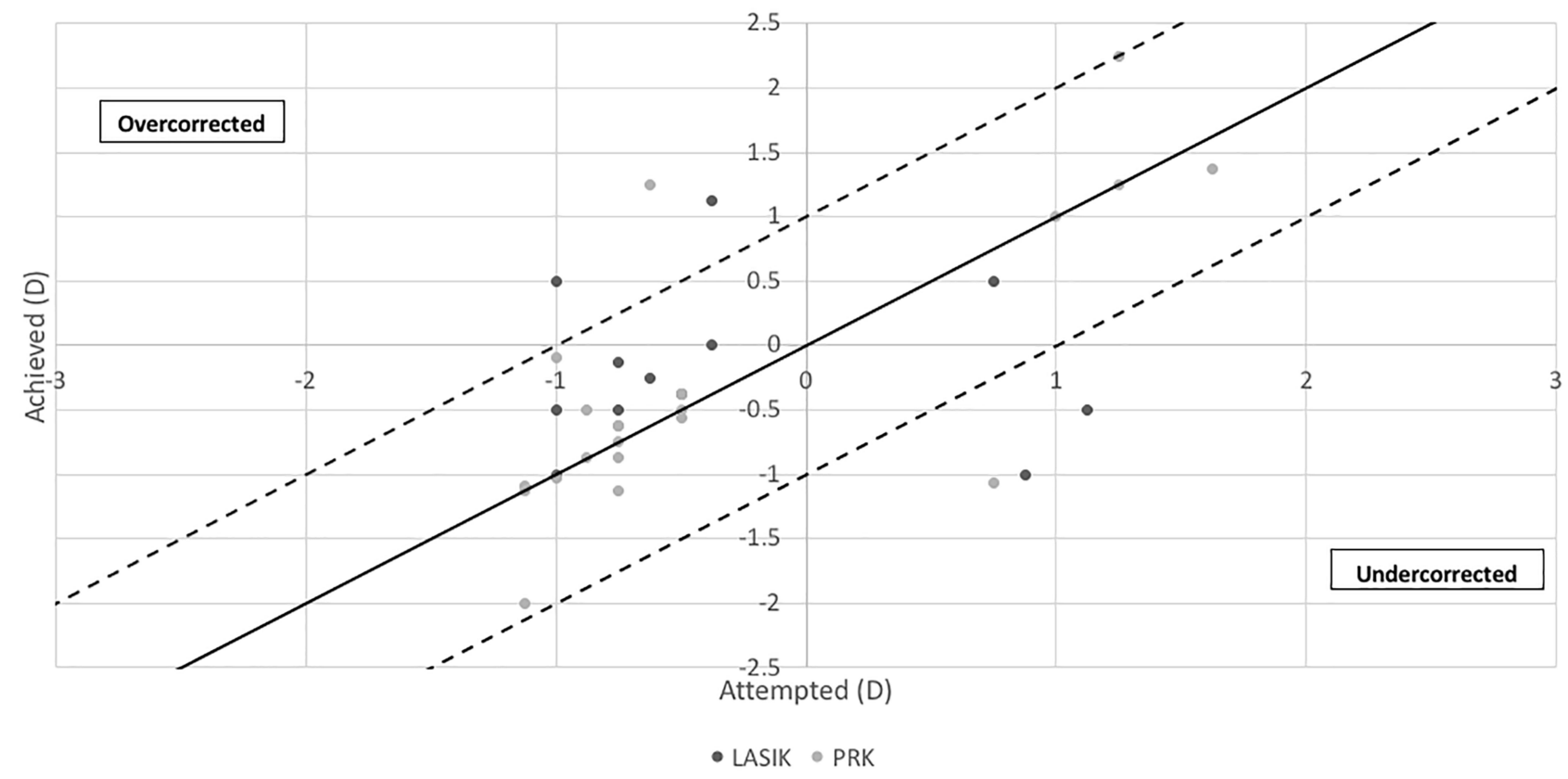

Figure 3 Scattergram of the ability to achieve emmetropia at the last post-operative visit.

hundred percent of LASIK eyes and $89.5 \%$ of PRK eyes were within \pm 0.50 diopters of emmetropia and $41.7 \%$ of LASIK eyes and $52.6 \%$ of PRK eyes were within \pm 0.13 diopters of emmetropia (Figure 2). Eighty-three \% of LASIK and $70 \%$ of PRK retreated eyes were within 0.25 diopters of astigmatism. In addition, there was no significant difference in the scatter of predictability of attempted versus achieved emmetropia (Figure 3).

Preoperative cylinder was $0.48 \pm 0.38$ diopters and $0.58 \pm 0.23$ diopters in PRK and LASIK retreated eyes,

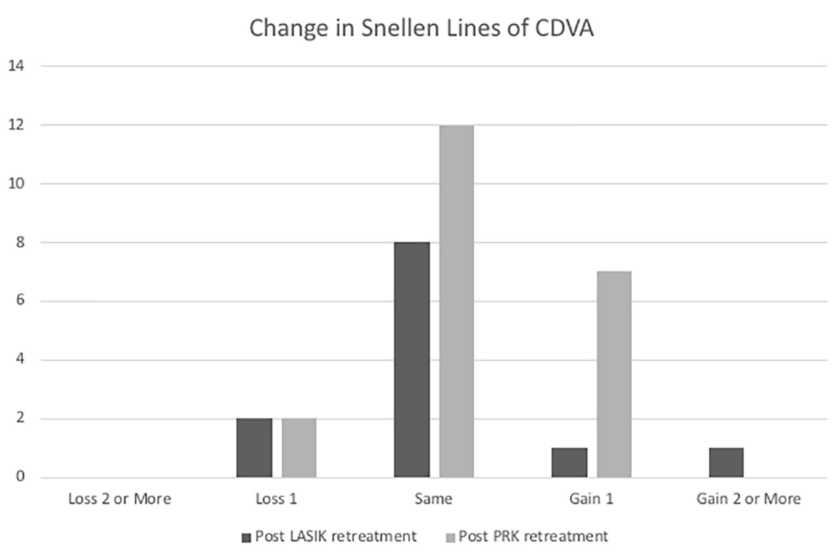

respectively $(\mathrm{p}=0.38)$. Eyes in the LASIK retreatment group had a postoperative cylinder of $0.13 \pm 0.20$ diopters and eyes in the PRK retreatment group had a postoperative cylinder of $0.28 \pm 0.25$ diopters $(\mathrm{p}=$ 0.07). LASIK retreatment eyes had an average spherical aberration of $0.18 \pm 0.21$ microns and PRK retreatment eyes had a spherical aberration of $0.13 \pm 0.18$ microns $(\mathrm{p}=0.21)$. In addition, coma, trefoil, and root-meansquare (RMS) error were not statistically significant between the two study groups.

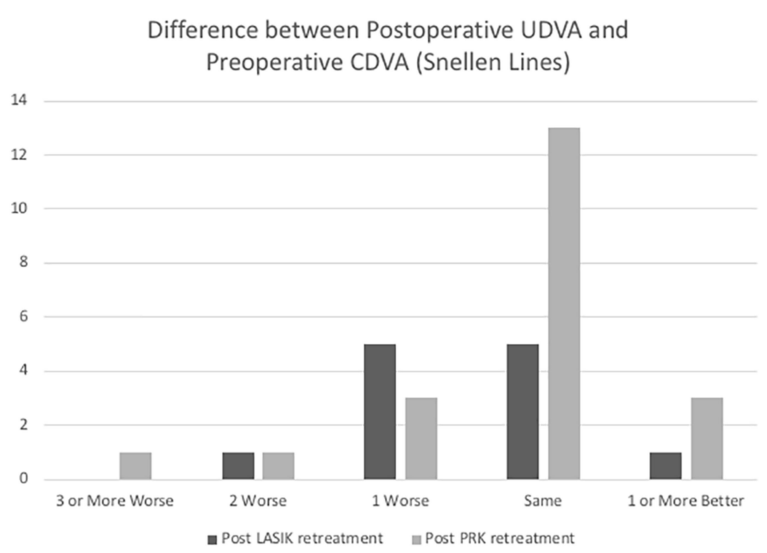

Figure 4 Comparing safety of LASIK and PRK retreatment. Change from preoperative best-corrected distance visual acuity (BCVA, left). Postoperative uncorrected distance visual acuity (UDVA) compared to preoperative BCVA (right). 
At the last follow-up visit, $9.1 \%$ and $26.3 \%$ of eyes gained one or more Snellen lines of best-corrected distance visual acuity (CDVA) after LASIK and PRK retreatment, respectively (Figure 4). 18.2\% of LASIK retreated eyes and $15.8 \%$ of PRK retreated eyes lost one or more lines of CDVA, demonstrating comparable safety profiles between the two groups. Sixty-seven percent of LASIK retreated and 59\% of PRK retreated eyes had no change in Snellen lines of CDVA.
The stability of refraction was similar in the two groups (Figure 5).

One eye with previous LASIK surgery which underwent LASIK retreatment had epithelial ingrowth that was detected and removed at the post-operative month 1 visit without complication or recurrence. There were no other notable significant or adverse events during or after the retreatment procedure.

\section{Spherical Equivalent Refraction Stability}
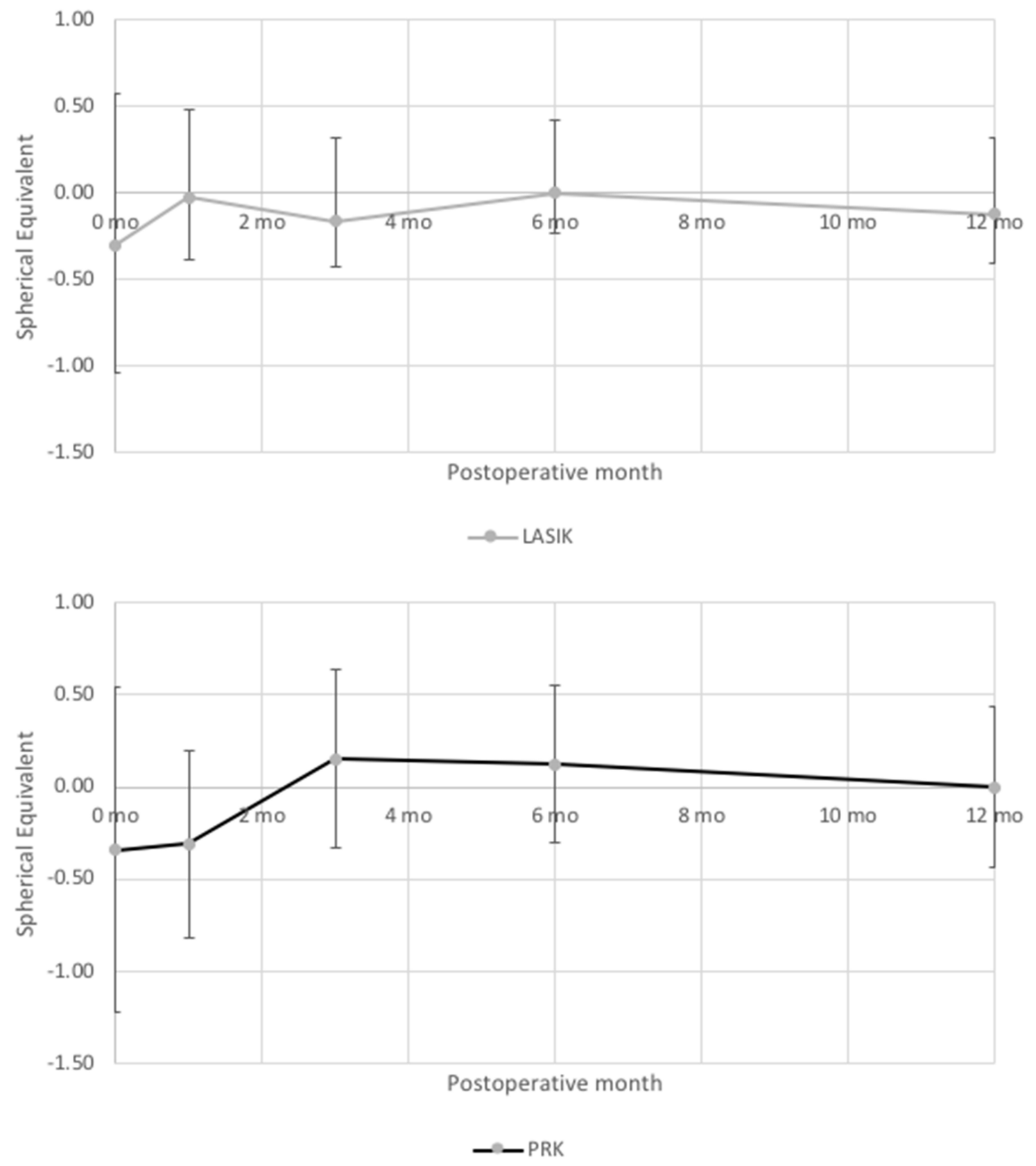

Figure 5 Stability of refraction over time after LASIK (top) and PRK enhancement surgery (bottom). 


\section{Discussion}

When deciding between LASIK and PRK procedures for retreatment, providers may balance the shorter post-op recovery period and lower rates of corneal haze of LASIK with the potential additional risk of epithelial ingrowth. There are other additional factors to consider, such as time since the first surgery and residual corneal thickness. In our prospective study, we found little evidence to suggest any difference in safety profiles between retreatment with PRK or LASIK.

As with primary LASIK and PRK, both retreatment procedures were overall found to have minimal changes in CDVA or spherical equivalent refraction. While no eye lost more than two lines of CDVA, $18.2 \%$ of LASIK retreated eyes and $15.8 \%$ of PRK retreated eyes lost one or more lines of CDVA, which is not an insignificant when considering possible LASIK and/or PRK retreatment. At the final follow-up visit, there were no statistically significant differences in eyes with LASIK or PRK retreatment when evaluating residual refractive error and induced aberrations. One eye in the LASIK retreatment cohort developed epithelial ingrowth at the postoperative month one visit $(8.3 \%$ of eyes who underwent LASIK enhancement); given the modest sample size of the study, the 12 eyes that underwent LASIK retreatment may not be sufficient to adequately detect the rate of epithelial ingrowth. The relatively low rate of epithelial ingrowth compared to prior studies may be attributed to our strict inclusion criteria that all patients who underwent LASIK retreatment must have had prior LASIK surgery within 2 years. Difficulty with lifting the LASIK flap, which increases over time, may impact the potential rate of epithelial ingrowth.

While these results suggest comparable efficacy and accuracy for both LASIK and PRK as retreatment procedures, the spread of predictability is better with LASIK retreated eyes. The standard deviation in achieved spherical equivalent was 0.24 with LASIK and 0.43 with PRK, and $10 \%$ of patients with PRK re-treated eyes versus $0 \%$ of LASIK re-treated eyes had post-retreatment spherical equivalent refraction greater than 0.50 diopters. The higher spread of predictability of eyes retreated with PRK may be attributed to irregular epithelial remodeling, a known drawback of this procedure. ${ }^{29-32}$ In addition, residual astigmatism was lower in the LASIK retreated eyes compared to the PRK retreated eyes but did not reach statistical significance. We postulate that there is a trend toward more accurate astigmatic correction with LASIK but more data is needed.

Though our efforts to optimize methodological quality include controlling for procedure variability through a single surgeon and site and ensuring our sample had similar bestcorrected visual acuity prior to primary refractive surgery, our study is not without limitations. Because of the excellent outcomes of primary keratorefractive surgery, the majority of patients have no need for retreatment, ultimately resulting in a modest sample size. This in turn affects the interpretation of our results. Similarly, though we found the amount of spherical equivalent and cylinder in the retreatment group to be small, it remains to be seen whether these results will change with a larger amount of residual refractive error. In addition, all patients who had PRK as their primary surgery did not qualify for LASIK as a retreatment option, and we were unable to evaluate outcomes following this specific retreatment series. Finally, while a contralateral eye study or randomized controlled study would have been ideal, this was not possible given the small number of patients requiring bilateral retreatment procedures.

In conclusion, our study demonstrates that as retreatment options for residual refractive error following previous keratorefractive surgery, both LASIK and PRK prove comparable in postoperative higher-order aberrations as well as all measures of safety, efficacy, and predictability. In future studies, power may be maximized through a multicenter study or by increasing the length of the study. In addition, adding variables of subjective quality of vision and patient satisfaction may also be useful when comparing the two procedures for retreatment.

\section{Funding}

Our institutions are supported by the Research to Prevent Blindness.

\section{Disclosure}

This paper was presented at the 2018 meeting of the American Society of Cataract and Refractive Surgery as a conference talk with interim findings. EEM: Equity in RxSight, Inc., and Placid0, Inc.; Equity and patents in VacuSite, LLC; Consultant for Avedro, Carl Zeiss Meditec, J\&J Vision; Sponsored research with Alcon, Allergan, Avedro, Carl Zeiss Meditec, and Presbia; and reports grants from Alcon Surgical, grants from Presbia, personal fees from Avedro, personal fees from Johnson \& Johnson Vision, sponsored research from Carl Zeiss Meditec, sponsored researchfrom Allergan, equity and 
patents in VacuMed, outside the submitted work. The authors report no other potential conflicts of interest for this work.

\section{References}

1. Hatch BB, Moshirfar M, Ollerton AJ, Sikder S, Mifflin MD. A prospective contralateral comparison of photorefractive keratectomy (PRK) versus thin-flap LASIK: assessment of visual function. Clin Ophthalmol. 2011;5:451-457.

2. Manche EE, Haw WW. Wavefront-guided laser in situ keratomileusis (LASIK) versus wavefront-guided photorefractive keratectomy (PRK): a prospective randomized eye-to-eye comparison (an American Ophthalmological Society thesis).. Trans Am Ophthalmol Soc. 2011;109:201-220.

3. Bower KS, Sia RK, Ryan DS, Mines MJ, Dartt DA. Chronic dry eye in photorefractive keratectomy and laser in situ keratomileusis: manifestations, incidence, and predictive factors. J Cataract Refract Surg. 2015;41:2624-2634. doi:10.1016/j.jcrs.2015.06.037

4. Nettune GR, Pflugfelder SC. Post-LASIK tear dysfunction and dysesthesia. Ocul Surf. 2010;8:135-145. doi:10.1016/S15420124(12)70224-0

5. Dawson DG, Randleman JB, Grossniklaus H, et al. Corneal ectasia after excimer laser keratorefractive surgery: histopathology, ultrastructure, and pathophysiology. Ophthalmology. 2008;115:2181-2219. doi:10.1016/j.ophtha.2008.06.008

6. Denoyer A, Landman E, Trinh L, Faure JF, Auclin F, Baudouin C. Dry eye disease after refractive surgery: comparative outcomes of small incision lenticule extraction versus LASIK. Ophthalmology. 2015;122(4):669-676. doi:10.1016/j.ophtha.2014.10.004

7. Barreto J, Barboni MT, Feitosa-Santana C, et al. Intraocular straylight and contrast sensitivity after contralateral wavefront-guided LASIK and wavefront-guided PRK for myopia. $J$ Refract Surg. 2010;26:588-593. doi:10.3928/1081597X-20090930-01

8. Bühren J, Martin T, Kühne A, Kohnen T. Correlation of aberrometry, contrast sensitivity, and subjective symptoms with quality of vision after LASIK. J Refract Surg. 2009;25:559-568.

9. Keir NJ, Simpson T, Jones LW, Fonn D. Wavefront-guided LASIK for myopia: effect on visual acuity, contrast sensitivity, and higher order aberrations. J Refract Surg. 2009;25:524-533. doi:10.3928/ 1081597X-20090512-06

10. Kim TW, Wee WR, Lee JH, Kim MK. Contrast sensitivity after LASIK, LASEK, and wavefront-guided LASEK with the VISX S4 laser. J Refract Surg. 2007;23:355-361. doi:10.3928/1081-597X20070401-07

11. Ang M, Ho H, Fenwick E, et al. Vision-related quality of life and visual outcomes after small-incision lenticule extraction and laser in situ keratomileusis. J Cataract Refract Surg. 2015;41:2136-2144.

12. Lee MD, Manche EE. Quality of vision after wavefront-guided laser in situ keratomileusis or photorefractive keratectomy: contralateral eye evaluation. J Cataract Refract Surg. 2017;43:54-59. doi:10.1016/ j.jcrs.2016.10.021

13. Chua D, Htoon HM, Lim L, et al. Eighteen-year prospective audit of LASIK outcomes for myopia in 53731 eyes. Br J Ophthalmol. 2019;103(9):1228-1234. doi:10.1136/bjophthalmol-2018-312587

14. Pokroy R, Mimouni M, Sela T, Munzer G, Kaiserman I. Predictors of myopic photorefractive keratectomy retreatment. J Cataract Refract Surg. 2017;43(6):825-832. doi:10.1016/j.jcrs.2017.06.001
15. Randleman JB, White AJ, Lynn MJ, Hu MH, Stulting RD. Incidence, outcomes, and risk factors for retreatment after wavefront-optimized ablations with PRK and LASIK. J Refract Surg. 2009;25:273-276. doi:10.3928/1081597X-20090301-06

16. Lin RT, Maloney RK. Flap complications associated with lamellar refractive surgery. Am $J$ Ophthalmol. 1999;127:129-136. doi:10.1016/S0002-9394(98)00320-1

17. Rojas MC, Lumba JD, Manche EE. Treatment of epithelial ingrowth after laser in situ keratomileusis with mechanical debridement and flap suturing. Arch Ophthalmol. 2004;122:997-1001. doi:10.1001/ archopht.122.7.997

18. Walker MB, Wilson SE. Incidence and prevention of epithelial growth within the interface after laser in situ keratomileusis. Cornea. 2000;19:170-173. doi:10.1097/00003226-200003000-00009

19. Chang JSM. Complications of sub-Bowman's keratomileusis with a femtosecond laser in 3009 eyes. J Refract Surg. 2008;24:S97S101. doi:10.3928/1081597X-20080101-17

20. Kamburoğlu G, Ertan A. Epithelial ingrowth after femtosecond laser-assisted in situ keratomileusis. Cornea. 2008;27:1122-1125. doi:10.1097/ICO.0b013e3181731439

21. Wang MY, Maloney RK. Epithelial ingrowth after laser in situ keratomileusis. Am J Ophthalmol. 2000;129:746-751. doi:10.1016/ S0002-9394(00)00357-3

22. Chan CC, Boxer Wachler BS. Comparison of the effects of LASIK retreatment techniques on epithelial ingrowth rates. Ophthalmology. 2007;114(4):640-642. doi:10.1016/j.ophtha.2006.06.062

23. Caster AI, Friess DW, Schwendeman FJ. Incidence of epithelial ingrowth in primary and retreatment laser in situ keratomileusis. $J$ Cat Refract Surg. 2010;36:97-101. doi:10.1016/j. jcrs.2009.07.039

24. Broderick KM, Sia RK, Ryan DS, et al. Wavefront-optimized surface retreatments of refractive error following previous laser refractive surgery: a retrospective study. Eye Vis. 2016;3:3. doi:10.1186/ s40662-016-0034-x

25. Jin GJ, Merkley KH. Retreatment after wavefront-guided and standard myopic LASIK. Ophthalmology. 2006;113:1623-1628.

26. Kashani S, Rajan M, Gartry D. Wavefront-guided retreatment after primary wavefront-guided laser in situ keratomileusis in myopes and hyperopes: long-term follow-up. $\mathrm{Am} J$ Ophthalmol. 2009;147:417-423. doi:10.1016/j.ajo.2008.09.017

27. Montague AA, Manche EE. CustomVue laser in situ keratomileusis treatment after previous keratorefractive surgery. $J$ Cataract Refract Surg. 2006;32:795-798. doi:10.1016/j.jcrs.2006.01.081

28. Schallhorn SC, Venter JA, Hanna SJ, Hettinger KA, Teenan D. Flap lift and photorefractive keratectomy enhancements after primary laser in situ keratomileusis using a wavefront-guided ablation profile: refractive and visual outcomes. $J$ Cataract Refract Surg. 2015;41:2051-2512. doi:10.1016/j.jcrs.2015.05.031

29. Hersh PS, Schwartz-Goldstein BH. Corneal topography of phase III excimer laser photorefractive keratectomy. Characterization and clinical effects. Summit photorefractive keratectomy topography study group. Ophthalmology. 1995;102:963-968. doi:10.1016/S01616420(95)30927-X

30. Abbas UL, Hersh PS. Early corneal topography patterns after excimer laser photorefractive keratectomy for myopia. J Refract Surg. 1999;15:124-131.

31. Jin H, Wang D, Li Z. Corneal topographic analysis after excimer laser photorefractive keratectomy. Chin J Ophthalmology. 1998;34:53.

32. Abbas UL, Hersh PS. Natural history of corneal topography after excimer laser photorefractive keratectomy. Ophthalmology. 1998;105:2197-2206. doi:10.1016/S0161-6420(98)91216-7 


\section{Publish your work in this journal}

Clinical Ophthalmology is an international, peer-reviewed journal covering all subspecialties within ophthalmology. Key topics include: Optometry; Visual science; Pharmacology and drug therapy in eye diseases; Basic Sciences; Primary and Secondary eye care; Patient Safety and Quality of Care Improvements. This journal is indexed on PubMed

Submit your manuscript here: https://www.dovepress.com/clinical-ophthalmology-journal
Central and CAS, and is the official journal of The Society of Clinical Ophthalmology (SCO). The manuscript management system is completely online and includes a very quick and fair peer-review system, which is all easy to use. Visit http://www.dovepress.com/ testimonials.php to read real quotes from published authors. 